\title{
Risk factors for childhood burns: a case-control study of Ghanaian children
}

Samuel N Forjuoh, Bernard Guyer, Donna M Strobino, Penelope M Keyl, Marie Diener-West, Gordon S Smith

\begin{abstract}
Study objective - To study risk factors for childhood burns in order to identify possible preventive strategies.

Design - Case-control design with pair matching of controls to cases in relation to age, sex, and area of residence. The cases and controls were identified by a community based, multisite survey. The effects of host and socioenvironmental variables reported by mothers were investigated in a multivariate analysis using conditional logistic regression.

Setting - A developing country setting the Ashanti Region in Ghana.

Participants - These comprised 610 cases aged $0-5$ years who had been burned (as evidenced by a visible scar) and 610 controls with no burn history.

Main results - The presence of a preexisting impairment in a child was the strongest risk factor in this population $(O R=6 \cdot 71 ; 95 \%$ CI $2 \cdot 78,16 \cdot 16)$. Other significant risk factors included: sibling death from a burn $(O R=4 \cdot 41 ; 95 \%$ CI $1 \cdot 16$, 16.68); history of burn in a sibling ( $O R=$ $1 \cdot 79 ; 95 \% \mathrm{CI} 1 \cdot 24,2 \cdot 58)$; and storage of a flammable substance in the home $(O R=$ $1 \cdot 51$; 95\% CI $1 \cdot 03 ; 2 \cdot 21)$. Maternal education had a protective effect against childhood burns, although this effect was not strong (OR $=0.76 ; 95 \% \mathrm{CI} 0.55,1.05)$.

Conclusions - Community programmes to ensure adequate child supervision and general child wellbeing, particularly for those with impairments, as well as parental education about burns are recommended, to reduce childhood burns in this region of Ghana. The public should be advised against storing flammable substances in the home.
\end{abstract}

(F Epidemiol Community Health 1995;49:189-193)

Burns are an important cause of mortality and disability in children in developing countries, ${ }^{1-8}$ but our knowledge of risk factors for these is limited. Even though the exact magnitude of the problem has not been documented, anecdotal evidence from clinical practice shows that children are burned frequently throughout Ghana. While no study has been conducted on the epidemiology of burns in Ghana, such studies have been undertaken in other developing countries. Most studies, however, are based on hospital records ${ }^{9-17}$ which are likely to underestimate appreciably the number of cases in a developing country since many people have no access to modern health care. We could identify only three population based studies, one of which is unpublished. ${ }^{1819}$ However, these studies were limited by small sample size, covered only a small geographical area, or both.

A further limitation of studies to date is that none used controls to draw valid inferences about the relative importance of risk factors. For example, Sridhar recommended constant supervision of children and insuring safe heating and cooking appliances. ${ }^{9}$ These are all plausible ways of preventing childhood burns, but without comparing the exposure to these putative risk factors within a control group of children, it is impossible to assess the importance of any of these factors.

In this study we report the results of a casecontrol investigation of risk factors for childhood burns in Ghanaian children aged $0-5$ years using a community based, multisite approach.

\section{Methods}

STUDY AREA AND IDENTIFICATION OF CASES AND CONTROLS

The Republic of Ghana is divided into 10 administrative regions. Ashanti Region, the study area, comprises 18 districts, and with an estimated population of 2.3 million, ${ }^{20}$ it is the most populous region in the country. A house to house survey was conducted in Ashanti between July and December 1992 to identify children aged $0-5$ years (0-71 months) who had been burned. A scar, evidence of the burn injury, had to be seen by the study investigators in order for subjects to be eligible for inclusion as cases in the study.

The sampling for the survey was based on a frame used for the 1988 Ghana demographic and health survey for the Ashanti Region. ${ }^{21}$ Fifty enumeration areas (EAs) or primary sampling units (PSUs), hereafter referred to as "study sites", were randomly selected with equal probability from a total of 2177 EAs in the region. A number of households were systematically selected from the study sites until about 300 children had been listed.

The head or caretaker of each selected house was seen. All children less than 6 years old residing in the house were counted. Mothers were asked about the presence of burn scars. Then the children were "checked" for the presence or absence of a burn scar. Data on the number of children and each child's burn scars 
were entered on a listing form by trained health inspectors and assistants. About 300 children were sampled per site yielding a total of 15742 children. This sample gave the study a $90 \%$ power of detecting a $40 \%$ reduction in risk between cases of burns and their controls (risk ratio $=0 \cdot 6$ ) with $95 \%$ certainty.

The final sampling procedure involved the selection of cases and controls from the completed list of children for a more detailed follow up survey. The study protocol was approved by the human subjects committee of the Johns Hopkins University School of Hygiene and Public Health and the Ministry of Health of Ghana.

Case selection A case was defined as a child aged 0-5 years with evidence of any type of burn by maternal report, confirmed by the inspecting assistant. No problems were encountered with getting subjects undressed, when it was necessary for scar or wound ascertainment.

Control selection A control was defined as a child aged 0-5 years old without any evidence of burn by maternal report. One control per case was selected from a list pair-matched to each case on age within 6 months, sex, and area of residence. Controls were selected from the pair-matched list by choosing the house closest to that of the case. In situations where the selected control could not be reached after two attempts, a substitute was selected from the next closest person on the list.

\section{FOLLOW UP INTERVIEW}

Approximately one to three months after the initial (listing) survey, mothers or the usual caretakers of the selected cases and controls were interviewed by trained medical student interviewers using a standard questionnaire. The questionnaire elicited information on the characteristics of the child, including age at time of the burn, sex, tribe, birth order, history of previous injury, sibling burn and sibling death from a burn, and his or her socioenvironment. This includes parental education, income, presence of parents at the time of the burn, family size, father's smoking habits, and hours spent away from home by the mother. Information on storage of flammable substances in the home and whether the family had received instruction about what to do for a burn was also obtained. Any child with hearing loss, difficulty in seeing, lameness, or a history of epilepsy or a convulsion, was considered to have a pre-existing impairment.

\section{BURN, IMPAIRMENT, AND DISABILITY}

ASSESSMENT

Maternal reports of childhood burns made to the health inspectors were confirmed by the trained medical student interviewers who sketched the areas of scars and depigmentation, as well as any impairment or disability on a burn assessment chart. The body surface area (BSA) burned was estimated using the "rule of nines" modified for children. ${ }^{22}$ In addition, 50 completed charts were randomly selected by the first author for verification purposes and the chart data were compared with the scars on the children.

\section{STATISTICAL ANALYSIS}

Statistical analyses were performed using $E P I$ $I N F O$ version $5^{23}$ software on a personal computer and $S A S^{24}$ and EGRET/PECAN ${ }^{25}$ software on a mainframe computer.

We first compared our study sample with the regional population on selected demographic variables to ensure that the sample was representative of the region. Of the 955 children listed in the survey as having ever been burned, completed interviews were obtained with the mothers of $630(66 \%)$, of whom 20 had been burned twice. We could not interview the mothers in four of the 50 study sites ( 85 children) because these areas were inaccessible by ordinary vehicle due to bad weather. The dwelling places of 36 other children could not be located. A further 59 children had relocated and could not be traced. Finally, 145 children were absent after two visits. The characteristics of the interviewed children were compared with those of the children not interviewed. These comparisons were performed using the $\chi^{2}$ statistic or the Fisher's exact test. All statistical tests were two tailed; the level of significance was set at $\alpha=0.05$.

We also excluded 20 cases for whom appropriate controls could not be identified. The analysis was carried out on the remaining 610 matched case-control pairs. Nominal categories were created for continuous variables (for example, mother's education), and variables measured with more than two levels (for example, father's occupation). First, the crude association of each independent variable with case-control status was examined to identify significant independent variables. Crude (unadjusted) odds ratios and $95 \%$ confidence intervals $(95 \%$ CI) were computed for each independent variable.

The next step in the analysis was the estimation of the putative risk factors using multiple logistic regression. The selection of risk factors for inclusion in multivariate analysis was based on their univariate association with case-control status, their inter-relationships or collinearity, their biological plausibility, and their distribution in the study population. Conditional logistic regression modeling was performed through: (1) identification of putative risk factors significant at $p=0 \cdot 10$ level in the univariate analysis; (2) fitting the multivariate models using the 0.20 level as a criterion for including variables in the model; and (3) recommendation of a final model based on evaluation of interaction effects, likelihood ratio testing among models, and goodness of fit assessment. ${ }^{26}$ Deviance, one of the summary statistics in logistic regression plays the central role in the assessment of the goodness of fit. Under the assumptions of a logistic model, the distribution of the deviance would approximate $\chi^{2}$ with $n-(p+1)$ degrees of freedom, where, $\mathrm{n}$ is the sample size and $\mathrm{p}$ is the number of variables in the selected model. 
Table 1 Comparison of the interviewed and non-interviewed subjects in the study of risk factors for childhood burns in Ashanti Region, Ghana

\begin{tabular}{llll}
\hline & $\begin{array}{l}\text { Interviewed } \\
\text { subjects } \\
(n=630)\end{array}$ & $\begin{array}{l}\text { Non-interviewed } \\
\text { subjects } \\
(n=325)\end{array}$ & Test \\
Characteristic & No (\%) & No (\%) & \\
\hline $\begin{array}{c}\text { Age (mths) } \\
0-11\end{array}$ & $7(1 \cdot 1)$ & $9(2 \cdot 8)$ & $\chi^{2}=4.99$ \\
$12-23$ & $45(7 \cdot 1)$ & $45(13 \cdot 8)$ & $\mathrm{p}<0.05$ \\
$24-35$ & $117(18 \cdot 6)$ & $63(19 \cdot 4)$ & \\
$36-47$ & $131(20 \cdot 8)$ & $89(27 \cdot 4)$ & \\
$48-59$ & $155(24 \cdot 6)$ & $55(16 \cdot 9)$ & \\
$60-71$ & $173(27 \cdot 5)$ & $64(19 \cdot 7)$ & $\chi^{2}=0 \cdot 18$ \\
Gender & & & \\
Male & $330(52 \cdot 4)$ & $183(56 \cdot 3)$ & \\
Female & $300(47 \cdot 6)$ & $142(43 \cdot 7)$ & \\
\hline
\end{tabular}

* Ages unknown for two interviewed subjects.

Table 2 Comparison of putative risk factors for childhood burns in cases and controls ( $n=1220)$, Ashanti Region, Ghana

\begin{tabular}{|c|c|c|c|c|}
\hline Factor & Level & $\begin{array}{l}\text { Case } \\
(n=610) \\
(\%)\end{array}$ & $\begin{array}{l}\text { Control } \\
(n=610) \\
(\%)\end{array}$ & Test \\
\hline $\begin{array}{l}\text { Storage of a flammable substance in the } \\
\text { home }\end{array}$ & $\begin{array}{l}\text { No } \\
\text { Yes }\end{array}$ & $\begin{array}{l}83 \\
17\end{array}$ & $\begin{array}{l}88 \\
12\end{array}$ & $\begin{array}{l}\chi^{2}=5.33 \\
\mathrm{p}<0.05\end{array}$ \\
\hline $\begin{array}{l}\text { Received instruction about what to do in } \\
\text { case of a burn }\end{array}$ & $\begin{array}{l}\text { No } \\
\text { Yes }\end{array}$ & $\begin{array}{l}59 \\
41\end{array}$ & $\begin{array}{l}66 \\
34\end{array}$ & $\begin{array}{l}\chi^{2}=6.19 \\
\mathrm{p}<0.05\end{array}$ \\
\hline Father's occupation & $\begin{array}{l}\text { None } \\
\text { Farming } \\
\text { Trading } \\
\text { Skilled } \\
\text { Other } \\
\text { DK }\end{array}$ & $\begin{array}{r}3 \\
26 \\
9 \\
32 \\
21 \\
9\end{array}$ & $\begin{array}{r}6 \\
27 \\
8 \\
27 \\
23 \\
9\end{array}$ & $\begin{array}{l}\chi^{2}=16.71 \\
\mathrm{p}<0.05\end{array}$ \\
\hline $\begin{array}{l}\text { Presence of pre-existing impairment in the } \\
\text { child }\end{array}$ & $\begin{array}{l}\text { No } \\
\text { Yes }\end{array}$ & $\begin{array}{r}92 \\
8\end{array}$ & $\begin{array}{r}99 \\
1\end{array}$ & $\begin{array}{l}\chi^{2}=28.62 \\
\mathrm{p}<0.01\end{array}$ \\
\hline Mother's education (y) & $\begin{array}{l}0 \\
1-6 \\
7-10 \\
11+ \\
\text { DK }\end{array}$ & $\begin{array}{r}24 \\
13 \\
53 \\
7 \\
3\end{array}$ & $\begin{array}{r}19 \\
15 \\
54 \\
8 \\
4\end{array}$ & $\begin{array}{l}\chi^{2}=6.61 \\
\mathrm{p}<0.05\end{array}$ \\
\hline Hours spent away from home by the mother & $\begin{array}{l}0 \\
1-4 \\
5-8 \\
9+ \\
D K\end{array}$ & $\begin{array}{r}11 \\
31 \\
42 \\
14 \\
2\end{array}$ & $\begin{array}{r}15 \\
33 \\
43 \\
8 \\
1\end{array}$ & $\begin{array}{l}\chi^{2}=14 \cdot 12 \\
\mathrm{p}<0 \cdot 01\end{array}$ \\
\hline No of siblings with a burn history & $\begin{array}{l}0 \\
1 \\
2+ \\
\mathrm{DK}\end{array}$ & $\begin{array}{r}78 \\
17 \\
2 \\
3\end{array}$ & $\begin{array}{r}86 \\
10 \\
1 \\
3\end{array}$ & $\begin{array}{l}\text { Fisher's } \\
\mathrm{p}<0 \cdot 01\end{array}$ \\
\hline No of siblings dead from a burn & $\begin{array}{l}0 \\
1+ \\
\mathrm{DK}\end{array}$ & $\begin{array}{r}94 \\
3 \\
3\end{array}$ & $\begin{array}{c}98 \\
1 \\
1\end{array}$ & $\begin{array}{l}\text { Fisher's } \\
\mathrm{p}<0.01\end{array}$ \\
\hline
\end{tabular}

$\mathrm{DK}=$ Don't know or remember.

Table 3 Crude (unadjusted) odds ratios (OR) and tests of significance for selected factors of observations with no missing data $(n=1112)$ from univariate conditional logistic models of risk factors for childhood burns, Ashanti Region, Ghana

\begin{tabular}{lccccc}
\hline Factor & Level & OR & $(95 \%$ CI $)$ & $p$ \\
\hline Presence of pre-existing impairment in the child & No & 1.00 & & \\
& Yes & 6.33 & $(2.68,14.98)$ & $<0.001$ \\
History of a sibling burn & No & 1.00 & & \\
& Yes & 1.89 & $(1.32,2.70)$ & $<0.001$ \\
History of a sibling death from a burn & No & 1.00 & & \\
& Yes & 4.67 & $(1.34,16.23)$ & 0.005 \\
Storage of flammable substances in the home & No & 1.00 & & \\
& Yes & 1.55 & $(1.08,2.24)$ & 0.02 \\
Whether the child's mother spend some hours & No & 1.00 & & \\
away from home & Yes & 1.40 & $(0.97,2.04)$ & 0.07 \\
Mother educated & No & 1.00 & & \\
& Yes & 0.81 & $(0.59,1.09)$ & 0.16 \\
Father employed & No & 1.00 & & \\
& Yes & 1.19 & $(0.83,1.71)$ & 0.35 \\
\hline
\end{tabular}

\section{Results}

REPRESENTATIVENESS OF THE STUDY POPULATION

A total of $15742(3 \%)$ children were identified in the survey from an estimated population of 522536 children under 6 years in the Ashanti Region. ${ }^{20}$ The age and sex distributions of the survey sample were comparable with those of the population of the region. However, a comparison of the interviewed and non-interviewed cases of burns showed that the interviewed subjects were significantly older $\left(\chi^{2}=4 \cdot 99\right.$, $\mathrm{p}<0.05) ; 27.5 \%$ of the interviewed subjects were aged $60-71$ months compared with $19 \cdot 7 \%$ of the non-interviewed subjects) (table 1). The distribution in relation to sex was nonetheless similar between the two groups.

\section{COMPARISON OF PUTATIVE RISK FACTORS IN THE} CASES AND CONTROLS

Evaluation of the putative risk factors for childhood burns indicated that the following variables were significantly different between the cases and controls $(p<0.05)$; (1) storage of a flammable substance in the home; (2) received instruction about what to do in case of a burn; (3) father's occupation; (4) presence of preexisting impairment in the child; (5) mother's education; (6) hours spent away from home by the mother; (7) number of siblings with a burn history; and (8) number of siblings who had died from a burn (table 2). Even though variable (2) was significantly associated with childhood burns, it was not included in the conditional logistic modeling. Its distribution in cases and controls suggested that more cases than controls might have been given instructions about what to do for a burn after the burn events happened. Therefore, the variable may not be a risk factor for burns, per se, but rather a result of the burn.

\section{ESTIMATED UNADJUSTED ODDS RATIOS}

Table 3 presents the unadjusted odds ratios from univariate conditional logistic models. The presence of a selected pre-existing impairment in the child was associated with the highest risk of childhood burns $(O R=6.33$; $95 \%$ CI $2.68,14.98$ ). The odds of a burn in a child with a history of sibling burn and in a child with a sibling death from a burn were nearly twice and four and a half times respectively that of a child with no such history.

Maternal education was found to be protective against childhood burns but its significance was only marginal $(\mathrm{OR}=0.81$; CI $0.59,1.09, p>0 \cdot 10)$. When the father's occupation was dichotomised into whether or not he was employed this was not associated significantly with a childhood burn $(\mathrm{p}<0 \cdot 30)$.

\section{ESTIMATED ADJUSTED ODDS RATIOS}

Results from two multivariate models, model A and model B, are shown in table 4. Because of its importance as a factor of interest in the study, the variable - mother educated - was included in the multivariate models, although 
Table 4 Adjusted odds ratios (OR) and tests of significance from two multivariate conditional logistic models ( $n=1112)$ of risk factors for childhood burns, Ashanti Region, Ghana

\begin{tabular}{|c|c|c|c|c|c|}
\hline Factor & Level & $\begin{array}{l}\text { Model } A \\
\text { OR } \\
(95 \% C I)\end{array}$ & $p$ & $\begin{array}{l}\text { Model B } \\
\text { OR } \\
(95 \% C I)\end{array}$ & $p$ \\
\hline $\begin{array}{l}\text { Presence of pre-existing } \\
\text { impairment in the child }\end{array}$ & $\begin{array}{l}\text { No } \\
\text { Yes }\end{array}$ & $\begin{array}{l}1 \cdot 00 \\
6 \cdot 63 \\
(2 \cdot 75,15 \cdot 97)\end{array}$ & $<0.001$ & $\begin{array}{l}1 \cdot 00 \\
6 \cdot 71 \\
(2 \cdot 78,16 \cdot 16)\end{array}$ & $<0.001$ \\
\hline History of a sibling burn & $\begin{array}{l}\text { No } \\
\text { Yes }\end{array}$ & $\begin{array}{l}1 \cdot 00 \\
1 \cdot 76 \\
(1 \cdot 21,2 \cdot 54)\end{array}$ & 0.003 & $\begin{array}{l}1 \cdot 00 \\
1 \cdot 79 \\
(1 \cdot 24,2 \cdot 58)\end{array}$ & 0.002 \\
\hline $\begin{array}{l}\text { History of a sibling death } \\
\text { from a burn }\end{array}$ & $\begin{array}{l}\text { No } \\
\text { Yes }\end{array}$ & $\begin{array}{l}1 \cdot 00 \\
4 \cdot 45 \\
(1 \cdot 17,16 \cdot 9)\end{array}$ & 0.028 & $\begin{array}{l}1 \cdot 00 \\
4 \cdot 41 \\
(1 \cdot 16,16 \cdot 68)\end{array}$ & 0.029 \\
\hline $\begin{array}{l}\text { Storage of a flammable } \\
\text { substance in the home }\end{array}$ & $\begin{array}{l}\text { No } \\
\text { Yes }\end{array}$ & $\begin{array}{l}1 \cdot 00 \\
1 \cdot 49 \\
(1 \cdot 02,2 \cdot 19)\end{array}$ & 0.039 & $\begin{array}{l}1 \cdot 00 \\
1 \cdot 51 \\
(1 \cdot 03,2 \cdot 21)\end{array}$ & 0.034 \\
\hline Mother educated & $\begin{array}{l}\text { No } \\
\text { Yes }\end{array}$ & $\begin{array}{l}1.00 \\
0.76 \\
(0.55,1.04)\end{array}$ & 0.094 & $\begin{array}{l}1.00 \\
0.76 \\
(0.55,1.05)\end{array}$ & 0.094 \\
\hline $\begin{array}{l}\text { Whether child's mother } \\
\text { spent any hours away } \\
\text { from home }\end{array}$ & $\begin{array}{l}\text { No } \\
\text { Yes }\end{array}$ & $\begin{array}{l}1.00 \\
1.26 \\
(0 \cdot 85,1 \cdot 87)\end{array}$ & $0 \cdot 25$ & & \\
\hline Deviance & & $645 \cdot 89$ & & $647 \cdot 23$ & \\
\hline
\end{tabular}

it was not significant at the univariate level. In the first multivariate model containing six variables, model A, whether or not the child's mother spent some hours away from home was not significant $(p>0 \cdot 20)$ and was excluded from the remaining models. Model $\mathrm{B}$ containing the five variables presence of pre-existing impairment in the child; history of a sibling burn; history of a sibling death from a burn; storage of a flammable substance in the home; and maternal education (mother educated) was found to be the best model using likelihood ratio testing (LRT) with model $A$ and other models. The odds ratio in this final multivariate model were very similar to the unadjusted odds ratios in table 3 .

There was no evidence of interaction between any of the significant variables. The deviance for the selected final multivariate model, model B, was 647.23 with degrees of freedom equal to 1106 (1112-5-1). The corresponding $p$ value was greater than 0.05 indicating that the observed data fit the model adequately.

\section{Discussion}

Using a community based multisite study, we evaluated several risk factors for childhood burns in Ghanaian children aged $0-5$ years. We took advantage of the fact that most burns leave permanent scars in dark skinned Ghanaian children. These scars enable a burn that occurred at a young age to be identified several years later, and thus we did not have to rely entirely on the mother's recall or medical records. Similar proxy measures of incidence have been used to measure the endemicity of African onchocerciasis using skin pigmentation or "leopard skin". ${ }^{27}$ The important risk factors for burns included: the presence of a preexisting impairment in the child, history of a sibling burn, history of a sibling death from a burn, storage of a flammable substance in the home, and lack of maternal education.
The major pre-existing impairments selected for evaluation have an overall low prevalence ( 47.5 per 1000 children) in the child population in this study. However, their effect on childhood burns was profound. Although no information was elicited regarding the specific causes of these impairments in the children, many of them are preventable. For example, simple audiometric examinations can lead to early detection of hearing defects, which can be corrected before they develop into serious hearing impairments. Measles and vitamin A deficiency are also common causes of vision problems, particularly in developing countries. ${ }^{28}$ Fortunately, both of these conditions are also preventable. A major cause of lameness, poliomyelitis, is also preventable through routine childhood immunisation. While epilepsy may not be wholly preventable, it can be controlled by effective use of anticonvulsants so as to prevent the seizures which place a child at greater risk of getting burned. ${ }^{29}$

The history of sibling burns and sibling burn related deaths in a family may be an indication of a serious lack in the supervision of young children, or it may signify the presence of a major environmental or social risk factor not examined in this study. Therefore, in addition to educating families about augmenting the level of supervision of children, especially in the kitchen where most burns occur, serious efforts at identifying other burn-causing environmental factors in future studies may be important. The establishment of community programmes is one way of ensuring adequate child supervision and general child wellbeing, particularly for children with impairments.

As with many case-control designs, several sources of bias may have been present in this study - specifically, bias due to recall and interview differences. Although great efforts were made to achieve complete and accurate data, some recall bias, especially in relation to the father's information and possible underascertainment of burn scars by mothers, could not be resolved. Information was obtained from $75 \%$ of mothers and $8 \%$ of fathers for the cases compared with $63 \%$ of mothers and $10 \%$ of fathers for the controls. In addition, the control respondents had to recall past exposures at the times of burns of their respective cases. While the cases had specific events (the burn events) to guide them, the controls had no such guiding events. This could lead to differential recall.

Interview bias, resulting from the interviewer's knowledge of the case-control status, was also a possible source of bias. It was not possible to blind the interviewers to this because they had to confirm status. This could have affected the way and manner in which questions on past exposures were asked.

Finally, inability to reach 325 children, listed with burns in the initial survey, at the follow up survey was a concern. The fact that the interviewed children were older than the noninterviewed ones implies that inferences based on age analysis may be inaccurate.

In conclusion, this study has shown that children with pre-existing impairments, a his- 
tory of sibling burn, storage of a flammable substance in their homes, and lack of maternal education are at a much higher risk of getting burned than others. In addition to establishing community programmes we recommend parental education about burns to reduce childhood burns in this region of Ghana. Secondly, we recommend that the public be educated about the hazards of storing flammable substances in the home. Thirdly, we recommend intervention trials on selected prevention strategies and subsequent programme evaluation of these strategies to assess their overall effect. Finally, we recommend that a more extensive study of disability and of other injury types in Ghana be conducted. These research activities could form the basis of an injury research and prevention programme in Ghana.

This research was carried out with the aid of grants from the Rockefeller Foundation African Dissertation Internship Award, New York, US (RF 91037) and the International Development Research Center, Ottawa, Canada (92-0217). Dr Forjuoh was sponsored by fellowships from the World Health Organization sponsored by fellowships from the World Health Organization, the Johns Hopkins University, the Dalhousie (Canada)/Kumasi

and Child Health Block Training Grant.
The authors are grateful to Professor Susan Baker for her The authors are grateful to Professor
generous contribution to this research.

1 Wintemute GJ, Baker SP, Mohan D, Teret S eds. Injur prevention in developing countries. Baltimore, MC: The
prester prevention in developing countries.

2 Manciaux M, Romer CJ. Accidents in children, adolescents and young adults: a major public health problem. World Health Stat $Q$ 1986;39:227-31.

3 Ghana Health Assessment Project Team. A quantitative method of assessing the health impact of different disease in less developed countries. Int $\mathcal{F}$ Epidemiol 1981;10:73-80.

4 Smith GS, Barss P. Unintentional injuries in developing countries: the epidemiology of a neglected problem. Epidemiologic Reviews 1991;13:228-66.

5 Onuba $\mathrm{O}$, Udoidiok E. Hospital management of massive burns in the developing countries. Burns 1987;13:386-90.

6 Sherif MM, Sato RM. Severe thermal hand burns - factors affecting prognosis. Burns 1989;15:42-6.

7 Curreri PW, Luterman A. Burns. In: Schwartz SI, Shires GT, Spencer FC eds. Principles of surgery. Vol I. 5th ed.
(n)
New York, St Louis, San Francisco: McGraw-Hill Book Company, 1989;285-305.

8 McLoughlin E, McGuire A. The causes, cost and prevention of childhood burns injuries. Am 7 Dis Child 1990;144: 677-83.

9 Sridhar RB. Burns in childhood and early adolescence. f Indian Med Assoc 1966;46:23-27.

10 Oluwasanmi JO. Burns in Western Nigeria. Br F Plast Surg 1969;22: 216-223.

11 Ofodile F, Norris J, Garnes A. Burns and child abuse. East Afr Med $₹$ 1979;56:26-9.

12 Lee ST. Two decades of specialized burns care in Singapore, 1961-1982. Ann Acad Med 1982;11:358-65.

13 Laditan AAO. Accidental scalds and burns in infancy and childhood. $\mathcal{F}$ Trop Pediatr 1987;33:199-202.

14 Karyoute SM, Badran DH. Analysis of 100 patients with thermal injury treated in a new burn unit in Amman, Jordan. Burns 1989;15:23-6.

15 Datubo-Brown DD, Kejeh BM. Burn injuries in Port Harcourt, Nigeria. Burns 1989;15:152-4

16 Jamal YS, Ardawi MSM, Ashy ARA, Shaik SA. Paediatric burn injuries in the Jeddah area of Saudi Arabia: a study of 197 patients. Burns 1990;16:36-40.

17 Cheng JCY Leung KS, Iam ZC-I Leung PC. An analysis of 1704 burn injuries in Hong Kong children. Burns 1990 ; 16:182-184.

18 Durrani KM (ed.). The epidemiology of burn injuries. 1st ed. Karachi: Mirror Press, 1971

19 Courtright P, Haile D, Kohls E. The epidemiology of burns in rural Ethiopia. $\mathcal{F}$ Epidemiol Community Health 1993;47: 19-22.

20 Ministry of Finance and Economic Planning. 1984 population census of Ghana. Demographic and economic characteristics, Ashanti Region. Accra, Ghana: Statistical Service, 1987.

21 Ghana Statistical Service. Ghana demographic and health survey 1988. Accra, Ghana. Columbia, MA: Institute for Resources Development/Macro Systems, 1989.

22 Wallace AB. The treatment of burns. London: Oxford Universty Press, 1941.

23 Dean AG, Dean JA, Burton AH, Dicker RC. Epi Info, Version 5: a wond processing, database, and statistics program for epidemiology on microcomputers. Stone Mountain, Georfor epidemiology on

24 SẢS Institute Inc., SAS language and procedures: Usage, version 6. Cary, NC: SAS Institute, 1989.

25 EGRET. Epidemiological graphics, estimation and testing package. Seattle, WA: Statistics and Epidemiology Research Corporation, 1988.

26 Hosmer DW, Lemeshow S. Applied logistic regression. New York: John Wiley \& Sons, 1989.

27 Edungbola LD, Alabi TO, Oni GA, Asaolu SO, Ogunbanjo BO, Parakoyi BD. 'Leopard skin' as a rapid diagnostic index for estimating the endemicity of African onchoserciasis. Int $\mathcal{f}$ Epidemiol 1987;16:590-4.

28 McLaren DS, Shirajain E, Tchallian M, et al. Xerophthalmia in Jordan. Am $\mathcal{f}$ Clin Nutr 1965;17:117-20.

29 Morselli PL, Pippenger CE, Penry JK (eds). Antiepileptic drug therapy in pediatrics. New York: Raven Press, 1983. 